\title{
An Economic Analysis of Wind Energy Harvest
}

\author{
Alper Atamtürk \\ Industrial Engineering \& Operations Research \\ University of California \\ Berkeley, California, 94720-1777 USA \\ Email: atamturk@berkeley.edu
}

\author{
Jane W. Lai, Leon E. Richartz, Huijie Li, Kevin Gu \\ GWI Wind Technology (Shanghai) Co. Ltd. \\ Rm 3102, 31/F, Sino Life Tower \\ 707, Zhangyang Rd, Pudong, Shanghai, China 200120 \\ Email: wind_technology@gwichina.com
}

\begin{abstract}
In this paper we develop a novel approach that simultaneously optimizes a wind farm and its financing for an improved economic analysis of wind energy projects. In our analysis we compare the energy yield of optimal wind energy projects with different turbine technologies under varying electricity price and wind speed scenarios. We perform extensive simulation studies and build statistical confidence intervals for the annual energy yield as well as the project's net present value at risk. The proposed approach eliminates the need for a trialand-error financial feasibility study and, consequently, improves the harvest of the wind energy.
\end{abstract}

\section{INTRODUCTION}

Worldwide wind energy installations are increasing rapidly. Nearly $37 \%$ of the 94 GW global wind energy capacity was added during 2006-07; wind power contributed 35\% (5 GW) of all new electric generating capacity in the U.S. in 2007 [1]. Economic and security concerns related to fossil fuels, climate change policies such as the Renewable Portfolio Standards enacted by the States, and the Federal Renewable Energy Production Tax Credits all contribute to the acceleration of wind energy developments in the United States. A recent report of the U.S. Department of Energy [2] envisions supplying 20\% the U.S. energy demand from wind by 2030 . China and India have also recognized the importance of wind as a clean and local source of energy for their rapidly growing economies. In China annual wind capacity installations have doubled each year since 2004 [3]. In April 2008 the Chinese National Development and Reform Commission revised its 11th Five Year Plan for installed wind power capacity from $5 \mathrm{GW}$ to $10 \mathrm{GW}$ by 2010; indeed, installations are expected to surpass the plans [4]. India's current Five Year Plan calls for more than doubling the installed wind energy capacity from $7 \mathrm{GW}$ to $17.5 \mathrm{GW}$ by 2012 [5, pg.387].

One consequence of the accelerating demand for wind energy has been rising turbine costs as turbine manufacturers find it hard to cope with the demand. After a long period of decline, turbine costs have risen steadily since 2002. In 2008 the average installed project cost is expected to reach to $\$ 2000 / \mathrm{kW}$ [1]. Another consequence is the depletion of easily accessible high wind sites. These two factors put the developers and investors in a difficult position. In the United States the development of wind projects is very much dependent on the availability of Federal Production Tax Credits [6]. The rapid growth is also forcing changes in turbine technologies to better utilize wind sites and allowing new turbine manufacturers from China and India to enter the markets with lower cost turbines.

Growing competition for the best wind sites puts an increased pressure for improving the energy yield of wind sites. For any given wind site, total energy production increases with the number of turbines installed; however, the addition of each turbine reduces the output per turbine due to wake effects. Thus from an investor's point of view, the internal rate of return of a project is higher if turbines are spaced at greater distances from each other to reduce the interaction among them; however doing so decreases the energy production per unit area of land. Thus, there is a fundamental trade-off between the rate of return of a wind energy project and the energy yield per unit area. The interaction between these two performance measures is complex and is a function of many factors, including the wind distribution at the site, turbine size and technology, configuration of the wind farm, financing structure of the project, electricity price, and the availability of tax incentives and carbon energy credits.

The current practice of wind energy project planning involves two steps. In the first step, one determines the size of the project by dividing the desired production capacity delivered to the grid by an approximate "capacity factor" (typically $25-45 \%$ depending on wind distribution at the site, turbine efficiency, and wake loss estimates for the planned farm configuration). In the second step, one checks whether the project can be financed at the desired rate of return and can meet the cash-flow requirements. If not, turbines are spaced farther apart to reduce wake losses and wind is wasted in order to make the project financially feasible. Often several iterations of ad-hoc adjustments in financing and farm plans are necessary between the two steps. The outcome is at best a feasible project, but typically far from optimal.

As wind becomes an increasingly valuable resource, in addition to improvements in the turbine technologies, a more systematic project development analysis is needed to improve the harvest of the available wind energy. Toward this end, we develop a novel approach that integrates the physical aspects of wind farm planning such as turbine spacing and wake effects into financing of the project. In particular, we build a mathematical optimization model that makes the financial structure of the project as well as the wind farm configuration explicit decision variables for maximizing the net present value of the project. Thus, we find an optimal wind farm 
configuration and its financing structure simultaneously to meet the investor's rate of return and cash flow requirements. In other words, rather than asking the question "Can we extract $x$ MWh annual energy from this wind site under certain spacing and financial assumptions?," we ask the question, better yet answer, "What is the best way of utilizing this wind site?" In doing so, we advance a financial feasibility study into a project finance optimization study. By making better use of the valuable wind sites, an integrated farm and project finance optimization increases harvested energy per unit area. Moreover, it can also make projects viable that would otherwise be found infeasible by an ad-hoc trial-anderror approach.

An integrated farm and project finance optimization is critical for developers and investors to assess the potential of a wind site and develop viable projects. It is also useful for governments for predicting more accurately the impact of tax incentives and electricity prices on wind energy production.

In our experimental analysis we compare the energy captured per unit area with different turbine technologies under varying electricity price and wind speed scenarios. We perform extensive simulation studies and build statistical confidence intervals for the annual energy production as well as the project's net present value at risk.

We find that the optimal financing structure, the turbine choice and farm configuration can be drastically different for sites with different wind speeds. Energy production, turbine choice, and configuration of the farm are very sensitive to wind speed and electricity prices.

\section{Integrated Wind Farm And Project Finance OPTIMIZATION}

We propose to design wind energy projects with an integrated wind farm and project finance optimization. Toward this end, we develop a multi-year financing model that maximizes the net present value of the project. In this model the decision variables are not only the loan amount, equity, monthly payments, depreciation, and taxes but also the size of the farm and the number of turbines in each row and column of the farm. As mentioned in the Introduction section, the spacing between turbines is a crucial factor in determining the total energy production of the farm due to the wake effects between turbines. Given interest rates, tax and depreciation rules, debt coverage ratios and desired rate of return on the investment, our optimization model finds the optimal configuration of the farm and the financing structure maximizing net present value of the project. The nonlinear mixed-integer optimization model is stated succinctly as follows:

Objective: Maximize net present value of the project. Constraints:

1) Loan: 15 -year fully amortized loan at $8 \%$ interest, paid back monthly over 15 years.

2) Equity: Minimum equity $20 \%$ and maximum equity $33 \%$ of the total project cost.
3) Taxes: Corporate taxes $0.0 \%, 7.5 \%$, and $15 \%$ assessed in years $1-2,3-5$, and $6-15$, respectfully. Tax credit at marginal rate of $6.5 \%$ for losses.

4) Depreciation: Straight-line depreciation over 15 years.

5) Debt coverage ratio: Annual net free cash minimum 1.3 and average 1.5 times the loan payments.

6) ATROI: Min $10 \%$ after tax rate of return on investment.

7) Wake effects: In order to compute the energy loss due to turbine wake, we implemented the Park Wake Model, developed by the Danish Riso National Laboratory [7], as modified in Garrad Hassan's wind farm design software WindFarmer [8].

8) Farm land availability constraints.

\section{ANALYSIS}

In this section we present our analysis of optimal wind energy projects at varying electricity prices and wind speeds for different turbines. We compare the annual energy yield per unit area, the levelized cost as well as the net present value of the projects over a range of electricity prices and wind speeds. Furthermore, we perform an extensive simulation study to assess the variability of the year-to-year energy output and compute the net present value at risk for the projects.

\section{A. Setup}

For this analysis we chose four different turbines in the 1.2-1.65 MW capacity range: Vestas V63 $(1500 \mathrm{~kW})$, Vestas V82 (1650 kW), Suzlon S64 (1250 kW), and GWIT JJ3 (1200 $\mathrm{kW}$ ). The first three are horizontal axis wind turbines (HAWT), whereas the last one is an extended height-to-diameter vertical axis turbine (EHD VAWT) with $42 \mathrm{~m}$ diameter and heightto-diameter aspect ratio 2.8. GWIT JJ3 [9] is an improved version of the EHD VAWT prototype studied in [10]. Energy production of all turbines are computed using the power curves provided by the manufacturers with air density 1.225 $\mathrm{kg} / \mathrm{m}$.sq. (sea level) and a Weibull wind distribution with shape parameter $k=2$. Suzlon and GWIT are low-cost turbines manufactured in India and China, respectively. We priced the European Vestas turbines at $\$ 2000 / \mathrm{kW}$ and Suzlon and GWIT turbines as $\$ 1400 / \mathrm{kW}$ to reflect pricing advantage of the low cost manufacturers. GWIT turbines utilize a direct drive train, rather than a gear box in order to reduce the operations and maintenance costs. Therefore, for operations and maintenance costs $\$ 0.0075 / \mathrm{kWh}$ is budgeted for the GWIT farm and $\$ 0.015 / \mathrm{kWh}$ for the others. All computations are done assuming a $3 \%$ electricity price tariff increase per year.

\section{B. Expected annual energy production of optimal farms}

Charts 1-3 show the expected annual production per $\mathrm{km}$ square of land for the optimal wind energy projects as a function of the electricity price. Charts 1,2 , and 3 are for mean wind speeds 7,8 , and $9 \mathrm{~m} / \mathrm{s}$, respectively. It is interesting to note that the energy production of the GWIT EHD VAWT farm is largest for all prices and wind speeds in the range examined. While the pricing advantage of Suzlon and GWIT turbines allow wind farms to be profitable even at low electricity prices, 


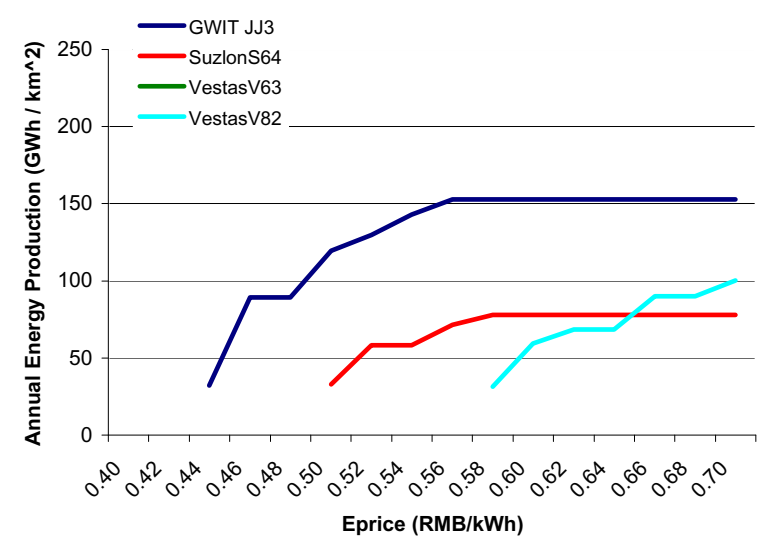

Chart 4 : Production vs Mean Wind Speed (0.52 RMB/kWh)

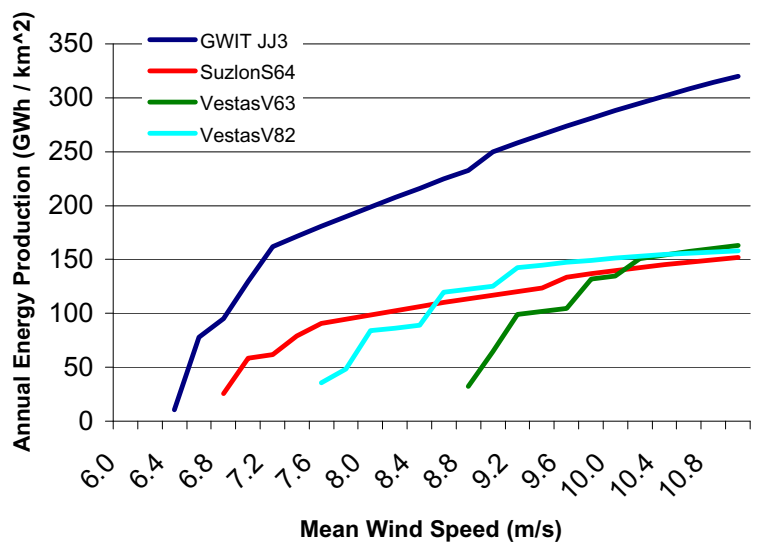

Chart 2 : Production vs Price $(8 \mathrm{~m} / \mathrm{s})$

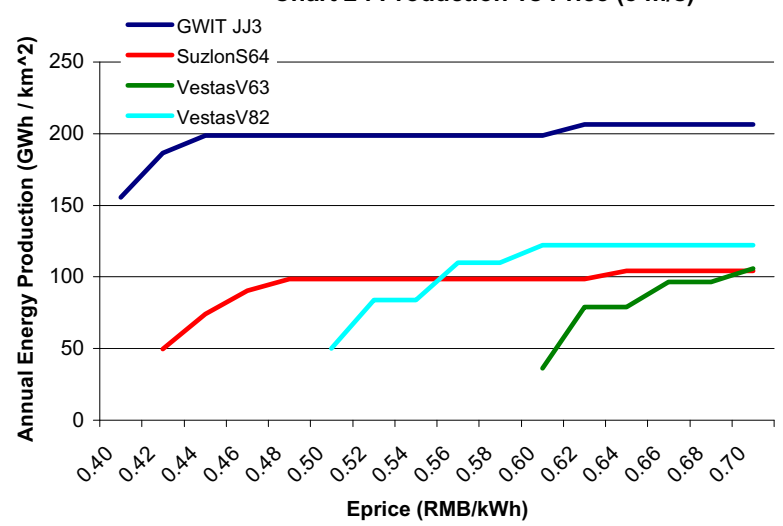

Chart 5 : Levelized Cost vs Mean Wind Speed (0.52 RMB/kWh)

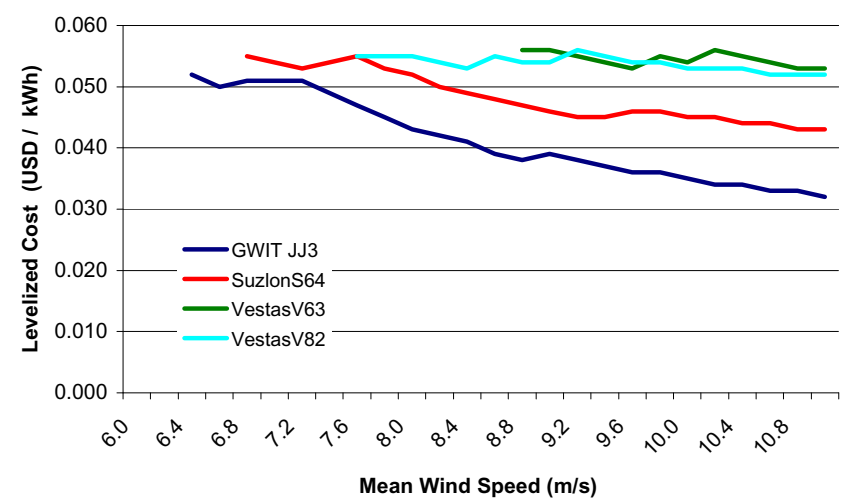

Chart 3 : Production vs Price $(9 \mathrm{~m} / \mathrm{s})$

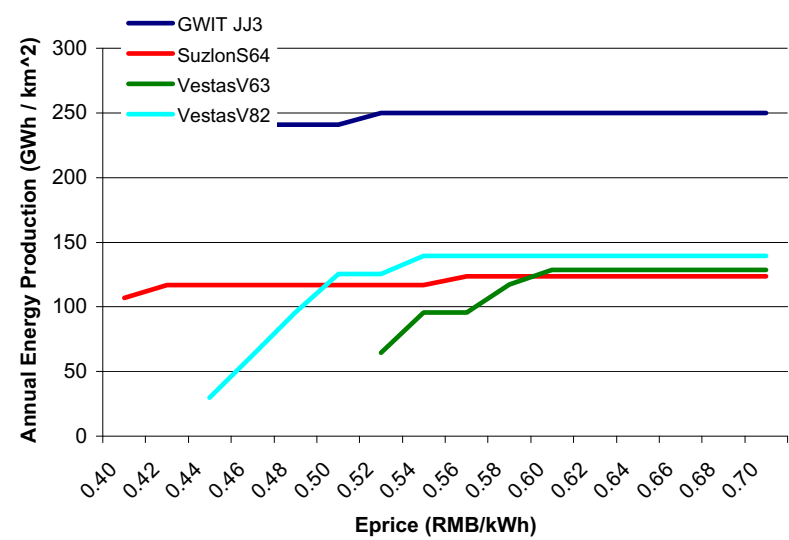

turbines in the same unit area. However, as the price of electricity increases it becomes more valuable to increase the density of the V82 turbines and surpass the yield of the Suzlon S64 farm. Vestas V63 farm is infeasible at $7 \mathrm{~m} / \mathrm{s}$ wind under our project finance assumptions.

A comparison of Charts 1-3 shows that as the wind speed increases, Vestas farms catch the Suzlon S64 farm yield at lower electricity prices. At $9 \mathrm{~m} / \mathrm{s}$ average wind speed Suzlon's price advantage diminishes except for electricity prices less than $0.50 \mathrm{RMB} / \mathrm{kWh}$. At any electricity price, the faster is the wind speed, the denser is the farm for all turbines. At low wind speeds and low electricity prices the financial constraints require sparser spacing of the turbines; though, optimal density is different for each turbine and is also a function of the project finance constraints.

Chart 4 shows the annual production as a function of wind because the GWIT turbine has a smaller diameter than Suzlon S64 (42m versus $64 \mathrm{~m})$, for a similar spacing it results in a larger capacity per $\mathrm{km}$ square; hence, the difference in the output levels.

At lower electricity prices the Suzlon S64 farm produces more energy per km square than the Vestas V82 farm even though Suzlon S64 is a smaller turbine. This is because the higher cost of Vestas V82 does not allow installing enough

speed at electricity price $0.52 \mathrm{RMB} / \mathrm{kWh}$. The energy yield of GWIT JJ3 is more than two times that of Suzlon S64 at all wind speeds. Due to its lower cost, at lower wind speeds the Suzlon S64 farm produces more per square area than the farms with larger Vestas turbines. The cost of the Vestas turbines does not justify installing enough turbines in the unit area until the wind speed reaches $8.6 \mathrm{~m} / \mathrm{s}$ for Vestas V82 and $10.2 \mathrm{~m} / \mathrm{s}$ 
for Vestas V63. Except for very high wind speeds the Vestas V82 farm produces more than the Vestas V63 farm. At wind speeds higher than $10.6 \mathrm{~m} / \mathrm{s}$ the V63 farm produces slightly more than the V82 farm. This is because V82's cut-out speed $(21 \mathrm{~m} / \mathrm{s})$ is lower than of V63 $(26 \mathrm{~m} / \mathrm{s})$.

\section{Expected levelized cost of energy}

The large production yield of the GWIT JJ3 farm shows its effect in cutting the levelized cost of energy at a faster rate as the wind speed increases. Chart 5 compares the levelized cost (USD/kWh) of energy for the optimal projects with different turbines as a function of the mean wind speed. The $30 \%$ lower price tag for the Suzlon and GWIT turbines shows its effect in the levelized cost of energy. The cost of energy at the Suzlon 64 farm is up to $17 \%$ cheaper than the Vestas farms; whereas the cost of energy at the GWIT JJ3 farm is up to $38 \%$ cheaper than the Vestas farms (at $11 \mathrm{~m} / \mathrm{s}$ mean wind speed).

\section{Annual production variability}

In this section we report our experiments on testing the variability of the annual energy output per unit area by the optimal projects. As wind is stochastic, annual energy production is rarely equal to its planned expected value and fluctuates year to year. Therefore, it is of interest to examine the variability of the production around its expected value to be able to assess the investment risk due to annual fluctuations of the wind.

For this purpose, given the optimal farm configuration and the financing structure from the optimization model, we simulate the wind daily for 15 years and observe the realized annual production levels per square $\mathrm{km}$. Our simulation program generates for each day of the duration of the project a wind speed from the Weibull distribution with shape parameter $k=2$ and the mean wind speed given for the site. Then the corresponding energy production is computed using the power curve of the turbines and the Park Wake Model. The experiment is repeated 100 times for accuracy.

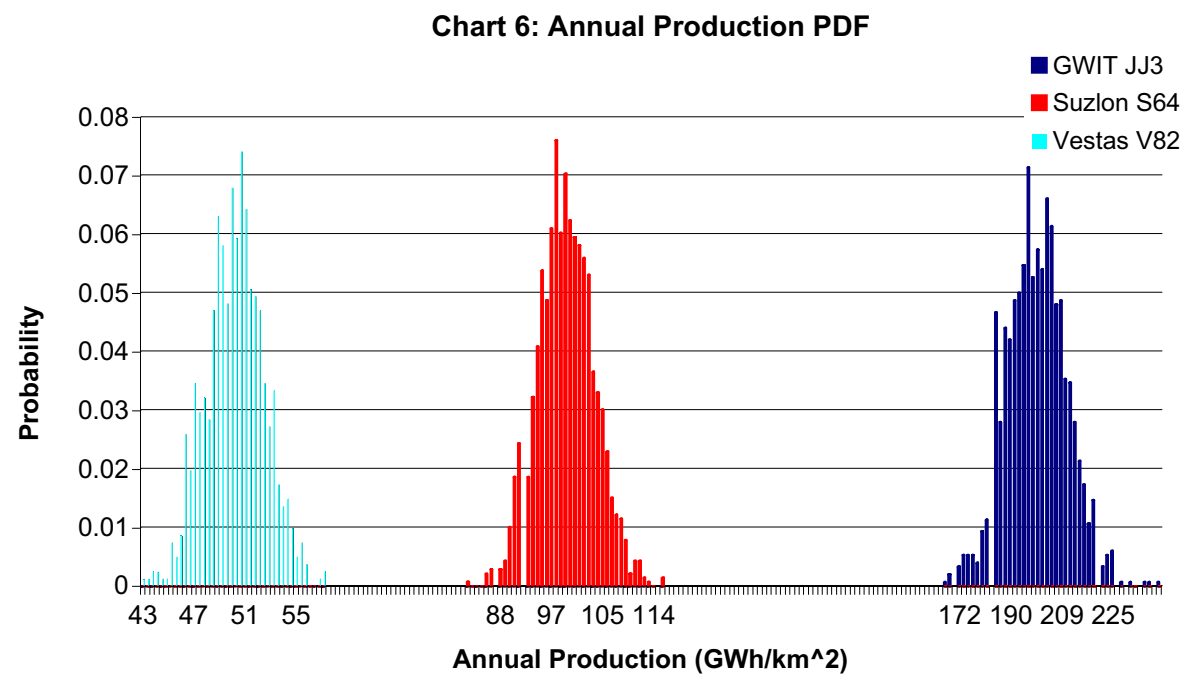

Chart 7: Net Present Value PDF

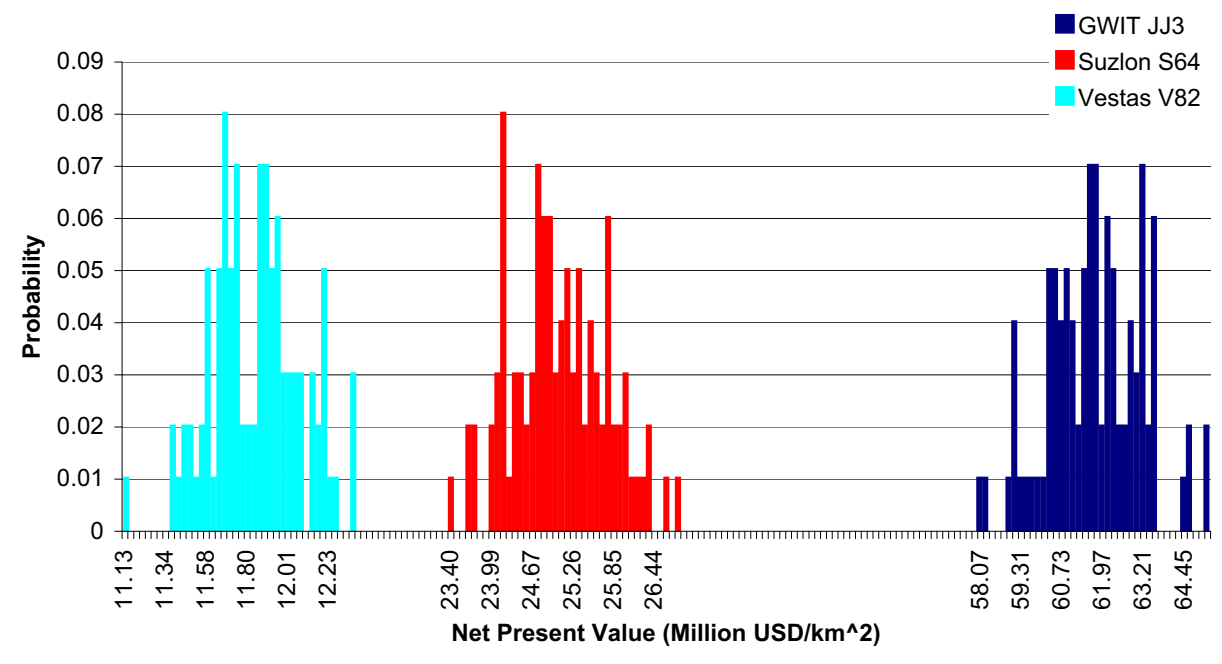


In Chart 6 we plot the empirical distribution of the annual production for GWIT JJ3, Suzlon S64, and Vestas V82 for a wind site with $8 \mathrm{~m} / \mathrm{s}$ mean wind speed and electricity price $0.52 \mathrm{RBM} / \mathrm{kWh}$ (subject to $3 \%$ annual tariff increase). Each distribution corresponds to $100 \times 15$ annual samples. By the Central Limit Theorem, the empirical distributions are close to Normal. The GWIT farm has 199.1 GWh average energy yield per $\mathrm{km}$ square and the annual yield is between $180.0 \mathrm{GWh}$ and $220.4 \mathrm{GWh}$ with $95 \%$ confidence. On the other hand, the Suzlon S64 farm yield is between 89.2 GWh and 108.6 GWh with $95 \%$ confidence and averages $98.8 \mathrm{GWh}$ per year per km square; whereas the yield for the Vestas V82 farm is between 45.8 GWh and $54.5 \mathrm{GWh}$ with $95 \%$ confidence and has an average of $50.2 \mathrm{GWh}$. The Vestas V63 farm is not financially feasible and therefore is not considered in the simulation study.

\section{E. Net present value at risk}

Finally, we compute the observed distribution of the net present value of the optimal projects using the simulation described in Section III-D. Once the annual energy production is determined by the simulator for each year, we run the corresponding cash flow analysis for the sample path in order to determine the actual payments, taxes, and the net free cash on hand, and consequently compute the observed net present value of the project.

The results of this simulation are presented in Chart 7. In this chart we plot the distribution of the 100 observed samples for the net present value of the optimal projects with the same three turbines. The empirical distributions deviate from Normal significantly. For the one $\mathrm{km}$ square farm area the mean present value of the GWIT project is 61.7 Million USD and it is no less than 58.8 Million USD with $98 \%$ probability. On the other hand, the mean net present value of the Suzlon S64 project is 25.0 Million USD and it is no less than 23.5 Million USD with $98 \%$ confidence; whereas the mean value of the Vestas V82 project is 11.8 Million USD and it is no less than 11.4 Million USD with $98 \%$ probability. While the coefficient of variation for the annual production is $4-5 \%$, the coefficient of variation for the net present value is about $2 \%$ for all three projects. The reduction in variability is due to aggregation of the value over the horizon of the project and the discounting effect.

\section{CONCLUDING REMARKS}

In this paper we have proposed a novel farm and project finance optimization approach, which bridges the gap between farm optimization and project finance, and eliminates the need for trial-and-error financial feasibility studies. Given interest rates, tax and depreciation rules, debt coverage ratios and desired rate of return on the investment, our optimization model finds the optimal configuration of the farm and the financing structure maximizing net present value of the project. We have demonstrated the use of the integrated optimization approach with an economic analysis of optimal wind energy projects as a function of electricity prices and mean wind speed for four different turbine types.
Our next step in improving the wind project optimization will be to allow utilizing multiple types of turbines in a single farm. We believe that there are economies to be gained in doing so since the pattern and speed of the wind changes as it moves through the farm.

We should caution, however, that our analysis is purely economical. It does not incorporate issues, such as, quality and reliability. Whereas cost and technical data on turbines are readily available, data on quality and reliability is scarce. Nevertheless, such considerations should also be part of any wind project development.

\section{REFERENCES}

[1] "Annual Report on U.S. Wind Power Installation, Cost, and Performance Trends: 2007," U.S. Department of Energy, May 2008.

[2] "20\% Wind Energy by 2030: Increasing Wind Energy's Contribution to U.S. Electricity Supply," U.S. Department of Energy, July 2008.

[3] "China Renewable Energy Development Overview - 2008," Energy Bereau of the National Development and Reform Commission, 2008.

[4] L. Schwartz and R. Hodum, "China's Wind Power Industry: Blowing Past Expectations," RenewableEnergyWorld.Com, June 2008.

[5] "11th Five Year Plan 2007-12: Volume III," Planning Commission, Government of India, 2007.

[6] R. Wiser, M. Bolinger, and G. Barbose, "Using the Federal Production Tax Credit to Build a Durable Market for Wind Power in the United States," Lawrence Berkeley National Laboratory, November 2007.

[7] I. Katic, J. Højstrup, and N. Jensen, "A Simple Model for Cluster Efficiency," European Wind Energy Association Conference and Exhibition, Rome, Italy, pp. 407-410, 1986

[8] GH WindFarmer: Theory Manual, Garrad Hassan, 2005.

[9] L. E. Richartz, L. Huijie, and G. Yi, "A New Super-Productive VAWT," September 2008, Submitted to Asia-Pacific Power and Energy Engineering Conference (APPEEC 2009).

[10] "Final Project Report: High-Energy Rotor Development, Test and Evaluation," Sandia National Laboratories, September 1996, Prepared by FloWind Corporation. 